\title{
The diagnosis of malignant breast lumps using fine needle aspiration cytology and ultrasonography versus histopathology
}

Abstract
Background and objective: The most common cancer of women worldwide is breast

Background and objective: The most common cancer of women worldwide is breast cancer and usually presents as a breast lump. Fine needle aspiration cytology and ultrasonography are two investigational techniques used to differentiate malignant breast lump from benign one. This study aimed to find out and compare the specificity, sensitivity, and predictive values of ultrasonography versus fine needle aspiration cytology for the diagnosis of malignant breast lump.

Methods: Patients who presented with clinically palpable breast lump at the department of Surgery, Rizgary Teaching Hospital, Erbil, from October 2014 to March 2016, were included. The age of the study participants ranged from 15 to 56 years. The highest rate $(28.9 \%)$ was among the age group $35-45$ years. Breast abscess, cystic breast lumps, and recurrent lumps have been excluded. The ultrasonographic evaluation was done by using 7.5 $\mathrm{MHz}$ probe for all patients at the department of radiology and fine needle aspiration cytology at the department of histopathology. All the patients underwent excision of the lumps, and histopathological examination was done for tissues. Specificity, sensitivity, and predictive values of ultrasonography and fine needle aspiration cytology were estimated, taking the histopathological result as the gold standard. A comparison of values was made. Results: Ninety patients with 93 breast lumps were included in this study. Fine needle aspiration cytology reported 28 lumps as malignant lumps and 63 as benign, and two cases were indeterminate. Ultrasonography reported 27 cases as malignant, 54 as benign, and nine as indeterminate, while three breast lumps were failed to be detected. Sensitivity, specificity, positive and negative predictive values of ultrasonography and fine needle aspiration cytology in diagnosing malignant breast lump were $94.74 \%, 100 \%, 100 \%$, $97.22 \%$, and $90.48 \%, 100 \%, 100 \%, 95.24 \%$,respectively.

Conclusion: Ultrasonography and fine needle aspiration cytology are $100 \%$ specific in diagnosing malignant breast lesions. Although ultrasonography appears more sensitive than fine needle aspiration cytology, it has a higher percentage of the indeterminate report.

Keywords: Fine needle aspiration cytology; Ultrasonography; Breast lumps.

\section{Introduction}

Cancer of the breast is the most common cancer affecting women worldwide and is the second most common cause of cancer death next to lung cancer. ${ }^{1}$ Due to the increasing incidence, mortality, and morbidity, breast cancer is the commonest malignant tumor responsible for $18.4 \%$ of all female cancers worldwide. ${ }^{2,3}$ It usually presents as a lump or nipple discharge. ${ }^{4}$ Breast lumps are, therefore, a cause of big anxiety both to the patient and also their family members. The main motive behind evaluating such a newly detected palpable lump is basically to rule out malignancy. ${ }^{1}$ Evaluation of breast lumps involves the rational use of history in detail, clinical breast examination, imaging facilities, and histopathological diagnosis. Though the final diagnosis is made by histopathological examination of the excised tissue, routine excision of all breast lumps would not be

${ }^{1}$ Department of Surgery, College of Medicine, Hawler Medical University, Erbil, I raq.

* Correspondence: aababan@yahoo.com 
rational because $80 \%$ of lumps are benign. ${ }^{5}$ Thus, the need is to utilize less invasive and cost effective method(s) of diagnosis without resorting to a more painful and invasive surgical biopsy. The modality should also be acceptable to the patient, accurate, easy to apply, reproducible, and must not need too much preparation. ${ }^{4}$ Given the common occurrence of breast cancer, It is important to accurately diagnose a clinically palpable breast lump with noninvasive techniques without routinely resorting to a formal biopsy which is much invasive. Therefore, this study is proposed to evaluate the accuracy of ultrasonography (USG), and fine needle aspiration cytology (FNAC) in the diagnosis of newly detected clinically palpable breast lumps in comparison to the final histopathological report of the biopsied specimens. This study aimed to compare the results of FNAC and USG in the diagnosis of newly detected clinically palpable breast lumps in the same population.

\section{Methods}

The study was conducted on both out-patients and in-patients presenting with clinically palpable breast lump(s) in the Department of General Surgery, Rizgary Teaching Hospital, Erbil, from $1^{\text {st }}$ October 2014 to $31^{\text {st }}$ March 2016. The term "palpable breast lump" meant the area of denser breast tissue felt different from the surrounding breast tissue and / or from a similar area of the contralateral breast, which could be subjectively felt. Recurrent lump at the same site of any previous operation and history of prior irradiation to chest or breast were excluded. Cystic breast lesions diagnosed clinically or by USG and breast abscess presenting as lump and yielding pus on aspiration were also excluded as such lesions were managed by aspiration or incision and drainage and were not excised. Informed consent was obtained. All patients underwent ultrasonographic evaluation at the Department of Radiology using
$7.5 \mathrm{MHz}$ probe. The reports were grouped into four categories for easy analysis as benign, indeterminate, malignant, and otherwise (failed to detect any lump). The cases were then sent to the aspiration cytology room (pathology) for FNAC examination of the breast lump. Small or non palpable lumps have been aspirated under the ultrasound guide. Aspiration was done using a disposable 23 gauge needle and $20 \mathrm{cc}$ syringe mounted on a suitable holder. Reports were collected and grouped into four categories as benign, malignant, indeterminate, and inadequate sample. Irrespective of USG and FNAC results, all the breast lumps were biopsied (excisional). The specimens were sent in formalin solution for histopathological examination at the Department of Pathology, Rizgary Teaching Hospital, Erbil. The final histopathological report was taken as the gold standard for diagnosis, and reports were grouped into benign and malignant for analysis. The study was approved by the Research Ethics Committee of the College of Medicine, Hawler Medical University, Erbil. An informed and verbal consent was taken from each participant. Data were analyzed by using the statistical package for the social sciences (SPSS, version 21). Both descriptive and analytic approaches were used. In the descriptive approach, we determined the frequencies and percentages. In the analytic approach, we used the Chi-square association test for categorical variables and McNemar test to determine the specificity, sensitivity, and predictive values of FNAC and USG, taking histopathological examination results as the gold standard. A $P$ value of $\leq 0.05$ was regarded as statistically significant.

-Sensitivity = True positive (TP)/ [TP+False Negative (FN)] X100

-Specify $=$ True Negative $(T N) /[T N+$ False positive (FP)] X100

-Positive Predictive value $(\mathrm{PPV})=\mathrm{TP} /$

(TP+FP) X100

-Negative Predictive value $(\mathrm{NPV})=\mathrm{TN} /$ $(\mathrm{FN}+\mathrm{TN}) \mathrm{X} 100$ 


\section{Results}

A total of 90 patients with 93 breast lumps (three patients had two lumps) were included in the study. The age ranged from 15 to 56 years, with a mean of 35.5 years. The demographic profile is shown in Table 1. Table 2 shows that the highest rate of lumps was in the upper outer quadrant $(36.5 \%)$, and the least was in the lower outer quadrant $(11.82 \%)$. Table 3 shows the highest percent of lumps were $3-4 \mathrm{~cm}$ in size $(41.9 \%)$.

Table 1: Demographic profiles of the 90 patients (93 lumps).

\begin{tabular}{lcc}
\hline Age in year & Number of patients & $\%$ \\
\hline$\leq 15$ year & 02 & 2.22 \\
$16-25$ year & 19 & 21.1 \\
$26-35$ year & 16 & 17.7 \\
$36-45$ year & 26 & 28.8 \\
$46-55$ year & 16 & 17.7 \\
$\geq 56$ year & 11 & 12.2 \\
Total & 90 & 100 \\
\hline
\end{tabular}

Table 2: Location of the lumps by the side, done by ultrasonography.

\begin{tabular}{lcccccccc}
\hline \multirow{2}{*}{ Side and location of lump (quadrant) } & \multicolumn{3}{c}{ Breast lumps } & \multicolumn{3}{c}{ Total } \\
& \multicolumn{2}{c}{ Right } & \multicolumn{2}{c}{ Left } & \multicolumn{3}{c}{} & \multicolumn{2}{c}{$\boldsymbol{P}$ value } \\
& No. & $\%$ & No. & $\%$ & No. & $\%$ & \\
\hline Upper-outer & 15 & 34.8 & 19 & 38 & 34 & 36.5 & \\
Lower-outer & 05 & 11.6 & 06 & 12 & 11 & 11.82 & \\
Sub areolar & 10 & 23.2 & 07 & 14 & 17 & 18.2 & 0.85 \\
Upper-inner & 08 & 18.6 & 11 & 22 & 19 & 20.4 & \\
Lower-inner & 05 & 11.6 & 07 & 14 & 12 & 12.9 & \\
Total & 43 & 100 & 50 & 100 & 93 & 100 & \\
\hline
\end{tabular}

Table 3: Malignant and benign breast lump size, defined by ultrasonography.

\begin{tabular}{|c|c|c|c|c|c|c|c|}
\hline \multirow{3}{*}{$\begin{array}{l}\text { Size of lump (Max } \\
\text { dimension in } \mathrm{cm} \text { ) }\end{array}$} & \multicolumn{6}{|c|}{ Breast lump } & \multirow{3}{*}{$P$ value } \\
\hline & \multicolumn{2}{|c|}{ Benign } & \multicolumn{2}{|c|}{ Malignant } & \multicolumn{2}{|c|}{ Total } & \\
\hline & No. & $\%$ & No. & $\%$ & No. & $\%$ & \\
\hline$\leq 1 \mathrm{~cm}$ & 03 & 4.8 & 00 & 00 & 03 & 3.2 & \\
\hline $1-<2 \mathrm{~cm}$ & 10 & 15.9 & 04 & 13.3 & 14 & 15 & \\
\hline $2-<3 \mathrm{~cm}$ & 16 & 25.4 & 03 & 10.0 & 19 & 20.4 & $0.15^{*}$ \\
\hline $3-<4 \mathrm{~cm}$ & 26 & 41.2 & 13 & 43.3 & 39 & 41.9 & \\
\hline$\geq 4 \mathrm{~cm}$ & 08 & 12.7 & 10 & 33.3 & 18 & 19.3 & \\
\hline Total & 63 & 100 & 30 & 100 & 93 & 100 & \\
\hline
\end{tabular}


Diagnosis of malignant breast lumps by FNAC ....

Zanco J. Med. Sci., Vol. 25, No. (1), April, 2021

https:/ / doi.org/ 10.15218/ zjms.2021.003

Table 4 shows that $45(48.4 \%)$ lumps were fibroadenoma, and $33(35.5 \%)$ were invasive ductal carcinoma. Table 5 shows the results of histopathological examination versus FNAC taking the histopathological examination as the gold standard.

Table 4: Results of the histopathological examination of the 93 breast lumps by the age of the patient.

\begin{tabular}{|c|c|c|c|c|c|c|c|}
\hline \multirow[t]{3}{*}{ Histopathological result } & \multicolumn{6}{|c|}{ Age (years) } & \multirow[t]{3}{*}{$P$ value } \\
\hline & \multicolumn{2}{|c|}{$\leq 35$} & \multicolumn{2}{|c|}{$>35$} & \multicolumn{2}{|c|}{ Total } & \\
\hline & No. & $\%$ & No. & $\%$ & No. & $\%$ & \\
\hline Fibroadenoma & 37 & 84 & 08 & 16.3 & 45 & 48.4 & $0.75^{*}$ \\
\hline Adenosis & 00 & 00 & 06 & 12.2 & 06 & 6.4 & \\
\hline Ductal hyperplasia & 02 & 4.6 & 03 & 6.1 & 05 & 5.4 & \\
\hline Papilloma & 00 & 00 & 01 & 2.0 & 01 & 1.07 & \\
\hline Ductal carcinoma in situ & 00 & 00 & 03 & 6.1 & 03 & 3.2 & \\
\hline Invasive ductal carcinoma & 05 & 11.4 & 28 & 57.1 & 33 & 35.5 & \\
\hline Total & 44 & 100.0 & 49 & 100.0 & 93 & 100.0 & \\
\hline
\end{tabular}

*Fisher Exacts test

Table 5: FNAC versus histopathological examination results.

\begin{tabular}{lcccc}
\hline FNAC result & Malignant & Benign & Total & $P$ value \\
\hline Malignant & 28 & 00 & 28 & $0.084^{*}$ \\
Benign & 03 & 60 & 63 & \\
Total & 31 & 60 & 91 & \\
\hline
\end{tabular}

*McNemar'stest 
Table 6 shows the results of USG >35 years). Table 7 shows the comparison versus histopathological results using histopathological examination as the gold standard and taking into consideration the age factor (overall age $\leq 35$ years and of FNAC versus USG sensitivity and specificity in diagnosing malignant breast lesions taking into consideration age factor (overall age $\leq 35$ years and $>35$ years).

Table 6: Results of USG v/s histopathological results using histopathological examination as gold standard taking into consideration age factor (overall age $\leq 35$ years and $>35$ years).

\begin{tabular}{|c|c|c|c|c|c|c|}
\hline & & & \multicolumn{3}{|c|}{ Histopathological result } & \multirow[b]{2}{*}{$P$ value } \\
\hline & & & Malignant & Benign & Total & \\
\hline \multirow{9}{*}{ USG result } & Overall & Malignant & 27 & 00 & 27 & $<0.001^{*}$ \\
\hline & & Benign & 03 & 51 & 54 & \\
\hline & & Total & 30 & 51 & 81 & \\
\hline & $\leq 35$ year of age & Malignant & 03 & 00 & 03 & $<0.001^{*}$ \\
\hline & & Benign & 00 & 36 & 36 & \\
\hline & & Total & 03 & 36 & 39 & \\
\hline & $>35$ years of age & Malignant & 23 & 00 & 23 & $<0.001^{*}$ \\
\hline & & Benign & 02 & 17 & 19 & \\
\hline & & Total & 25 & 17 & 42 & \\
\hline
\end{tabular}

${ }^{*}$ Fisher Exacts test

Table 7: Comparing FNAC versus USG sensitivity and specificity in the diagnosis of malignant breast lesion taking into consideration age factor (overall age $\leq 35$ years and $>35$ years).

\begin{tabular}{lcccc}
\hline & FNAC & Overall USG & $\begin{array}{c}\text { USG (for } \leq 35 \\
\text { years of age) }\end{array}$ & $\begin{array}{c}\text { USG (for } \mathbf{3 5} \\
\text { years of age) }\end{array}$ \\
\hline Sensitivity & $90.48 \%$ & $94.74 \%$ & $100 \%$ & $94.44 \%$ \\
$\begin{array}{l}\text { Specificity } \\
\begin{array}{l}\text { Predictive value of a positive } \\
\text { result (malignant report) }\end{array}\end{array}$ & $100 \%$ & $100 \%$ & $100 \%$ & $100 \%$ \\
$\begin{array}{l}\text { Predictive value of a negative } \\
\text { result (benign report) }\end{array}$ & $95.24 \%$ & $100 \%$ & $100 \%$ & $100 \%$ \\
\hline
\end{tabular}




\section{Discussion}

FNAC is an established and highly accurate method for diagnosing breast lesions. ${ }^{6}$ Although excisional biopsy is the 'gold standard' for the diagnosis of palpable breast lesions, in recent years, minimally invasive breast biopsy techniques, like core needle biopsy and FNAC, have become established for the diagnostic evaluation of breast lumps. ${ }^{7}$ A triple assessment consisting of clinical examination, mammography or USG, and FNAC or core biopsy is considered the gold standard in making a definitive diagnosis of breast lumps. ${ }^{8}$ These differences may be because of various inclusion criteria of a breast lump (like palpable or non palpable and lump size) and exclusion of inadequate results in other studies. The sensitivity and specificity of FNAC made the management of breast lumps easier for the surgeon and more beneficial for patients. The sensitivity usually ranges from $80 \%$ to $98 \%$, and the specificity may be up to $100 \% .^{9}$ It has also been found that sensitivity is dependent on the experience and skill of the aspirator. ${ }^{6}$ A wide variation in the sensitivity of USG in the diagnosis of malignant breast lumps ranging from $67 \%$ to $97 \%$ has been reported. ${ }^{10}$ This could be due to different methods of case selections, different resolution ability of ultrasound device used, and the fact that ultrasound is an operator dependent technique. When comparing USG with FNAC in the diagnosis of malignancy in breast mass, both were found to have $100 \%$ specificity and $100 \%$ positive informative value. Thus, a positive result for malignancy of either test can be considered confirmatory, and further treatment decisions can be made alone on this report without any further diagnostic investigation. A sensitivity result of FNAC of $90.48 \%$ in our study suggests that only 9.52 out of 100 cases having malignant lesions may be missed if FNAC is used alone for evaluation of breast lump. A sensitivity of $94.74 \%$ of USG means that a negative result of USG does not completely rule out the possibility of malignant lumps. Therefore, in the event of a negative result (benign lumps) of either, make physician seek additional tests to rule out malignancy should his clinical experience and skill suspect the malignant nature of the lump. The sensitivity of USG was found higher than that of FNAC (94.74\% against $90.48 \%$ ). Dysplasia also has a role in false negative results. ${ }^{11}$ These results give an impression that USG is a better tool than FNAC in ruling out the possibility of malignancy in breast lump. However, the percentage of the indeterminate result was very higher in USG than in FNAC ( 2 out of 93 in FNAC and 9 out of 93 in USG). Besides, two breast masses were not found by USG. In four patients where USG was indeterminate, FNAC could diagnose these lesions correctly, and in three patients with indeterminate results by USG, FNAC was wrong in diagnosing the lesions. In comparison, one case of indeterminate FNAC result has been correctly diagnosed as malignant by USG. So, both diagnostic investigations should be considered, and the physician should use the basis of his experience and clinical findings to choose either one or both of them. In a similar study by Reinikainen et al., to evaluate the accuracy of USG versus FNAC in diagnosing palpable solid breast lumps, they retrospectively reviewed the cytological results of 57 lesions with ultrasound and mammogram images of 84 palpable breast lumps. Results were compared to the histopathological diagnoses. Eighty-one out of the eighty four lesions (96\%) were diagnosed as a local abnormality by USG, thereby missing three lesions. Also, the sensitivity and specificity of FNAC were reported as $92 \%$ and $83 \%$, respectively. No false-negative malignancies in the three modalities were found (USG, FNAC, and mammography) combined. ${ }^{12}$ FNAC has become more reliable in the diagnosis of breast lumps. Although its use has led reduction in using frozen-section histology in about $80 \%$, false diagnosis is still 
commoner with FNAC than with histopathology. ${ }^{13}$ An additional important finding is that when we consider younger patients ( $\leq 35$ years of age), the specificity, sensitivity, positive and negative values of USG for diagnosing malignant breast lump were all $100 \%$ against the respective values of $94.44 \%, 100 \%, 100 \%$, and $92.86 \%$ when considering patients older than 35 years. The chances of missing the lump or indeterminate result were less in $\leq 35$ years of age group $(11.11 \% \mathrm{v} / \mathrm{s}$ $14.29 \%$ ). This obviously shows the more accuracy of USG in younger patients. The limitations of this study were that the size of the breast lump was not taken into consideration. Larger sized lumps are less likely to be missed in USG than the smaller ones. Also, abscess and cystic lesions were excluded in this study as they were treated mainly by drainage and aspiration, for which no tissue biopsy was taken for histopathological examination. An additional limitation was that the indeterminate cases were excluded in the calculation of sensitivity and specificity. The sensitivity of USG was higher than FNAC, but the rate of the conclusive report was higher in the case of FNAC than in USG. So, the calculated value of sensitivity did not reflect the limitation of USG versus FNAC. The age of the patient is known to affect the USG result, which is also proved in our study. There are also some strong points of this study. The gold standard test used in this study is the histopathological result which has been accepted as the gold standard internationally. A very strong point is the fact that both the USG radiologist and histopathologist performing the FNAC belonged to different departments of the hospital and therefore were blinded from each others' results, and both diagnostic tools in questions were tested upon the same study population. The effectiveness of these diagnostic studies in the evaluation of breast lump would depend on the experience and availability of these modalities and the age of the patients, and the clinicians' suspicion of the nature of the mass. In aged patients, the clinician may place USG at the lower level of preference since it is less accurate in the less dense breast. On the other hand, the examining clinician may better evaluate a FNAC result of malignancy for a hard, irregular lump in an adult female. Excisional biopsy must be the last option to obtain a pathological diagnosis. ${ }^{14}$ Some difficulties and limitations that need to be mentioned about FNAC. Both false-positive and false-negative results can occur. ${ }^{15}$ The most significant limitation in making a diagnosis is the overlapping features of different lesions. ${ }^{16}$ Therefore, both diagnostic tools should be considered complementary. Further procedures as FNAC under imaging guidance and immunohistochemistry may increase their accuracy.

\section{Conclusion}

FNAC is a cytological diagnostic tool, and USG an imaging tool. In this study, both techniques were found to give high positive, informative value in diagnosing malignant breast, therefore, giving the conclusion that a positive (malignant) result of either test are reliable in making a treatment decision. In this study, specificity was higher with USG than with FNAC, but the percentage of the conclusive report was higher with FNAC.

\section{Competing interests}

The author declares no competing interests.

\section{References}

1. Ferlay J, Shin HR, Bray F, Forman D, Mathers C, Parkin DM. Estimates of worldwide burden of cancer in 2008: GLOBOCAN 2008. Int J Cancer 2010; 127(12):2893-917.

2. Rahman MZ, Islam S. Fine needle aspiration cytology of palpable breast lump: A study of 1778 cases. Surgery 2013; S12:001.

3. Obaseki DE, Olu-Edo AN, Ogunbiyi JO. Diagnostic accuracy of fine needle aspiration cytology of palpable breast masses in Benin City, Nigeria. West Afr J Med 2010; 29(4):259-62.

4. Tiwari M. Role of fine needle aspiration cytology in diagnosis of breast lumps. Kathmandu Univ Med J 2007; 5(2):215-7. 
5. Pruthi S. Detection and evaluation of a palpable breast mass. Mayo Clin Proc 2001; 76:641-8.

6. Lieu D. Value of cytopathologist-performed ultrasound-guided fine-needle aspiration as a screening test for ultrasound-guided core-needle biopsy in non palpable breast masses. Diagn Cytopathol 2009; 37(4):262-9.

7. Ukah CO, Oluwasola OO. The clinical effectiveness of fine needle aspiration biopsy in patients with palpable breast lesions seen at the University College Hospital, Ibadan, Nigeria: A 10-year retrospective study. J Cytol 2011; 28(3):111-3.

8. Jindal U, Singh K, Kochhar A. Fine needle aspiration cytology of breast lumps with histopathological correlation: A four year and eight month study from rural India. Internet $\mathrm{J}$ Pathol 2012; 13:3.

9. Gukas ID, Nwana EJC, Ihezue CH, Momoh JT, Obekpa PO. Tru-cut biopsy of palpable breast lesions: A practical option for pre operative diagnosis in developing countries. Cent Afr J Med 2000; 46(5):127-30.

10. Ghazala M, Waqar F, Ghulam QB. Sonomammography for evaluation of solid breast masses in young patients. J Ayub Med Coll Abbottabad 2006; 18(2):34-7.

11. Homesh NA, Issao MA, El-Sofiani HA. The diagnostic accuracy of fine needle aspiration cytology versus core needle biopsy for palpable breast lumps. Saudi Med J. 2005; 26(1):42-46.

12. Reinikainen HT, Rissanen TJ, Piippo UK, Päivänsalo MJ. Contribution of ultrasonography and fine-needle aspiration cytology to the differential diagnosis of palpable solid breast lesions. Acta Radiol 1999; 40(4):383-89.

13. Rahman MZ, Sikder AM, Nabi SR. Diagnosis of breast lump by fine needle aspiration cytology and mammography. Mymensingh Med J 2011; 20(4):658-64.

14. Tham T-M, lyengar KR, Taib NA, Yip C-H. Fine needle aspiration biopsy, core needle biopsy or excision biopsy to diagnose breast cancer Which is the ideal method? Asian Pacific $J$ Cancer Prev 2009; 10:155-8.

15. Bukhari MH, Arshad M, Jamal S, Niazi S, Bashir S, Bakhshi IM, et al. Use of fine-needle aspiration in the evaluation of breast lumps. Patholog Res Int 2011; 2011:689521.

16. Bakhos R, Selvaggi SM, DeJong S, Gordon DL, Pitale SU, Herrmann M, et al. Fine-needle aspiration of the thyroid: rate and causes of cytohistopathologic discordance. Diagn Cytopathol 2000; 23(4):233-7. 